\title{
Hypoxia Induces Tumor Aggressiveness and the Expansion of CD133-Positive Cells in a Hypoxia-Inducible Factor-1 $\alpha$-Dependent Manner in Pancreatic Cancer Cells
}

\author{
Okito Hashimoto $^{a}$ Kazuya Shimizuc Shuho Semba ${ }^{c}$ Sachie Chiba ${ }^{b}$ \\ Yonson $\mathrm{Ku}^{\mathrm{b}}$ Hiroshi Yokozaki ${ }^{\mathrm{a}}$ Yuichi Hori $^{\mathrm{b}}$ \\ a Division of Pathology, Department of Pathology, and ${ }^{b}$ Division of Hepato-Billiary-Pancreatic Surgery, \\ Department of Surgery, Kobe University Graduate School of Medicine, and ' Department of Internal Medicine, \\ Kobe Medical Center, Kobe, Japan
}

\section{Key Words}

CD133 - Hypoxia - Pancreatic cancer • Cancer stem cell $\cdot$ Hypoxia-inducible factor- $1 \alpha \cdot \mathrm{CXC}$ chemokine receptor 4

\begin{abstract}
Background: Intratumoral hypoxia is known to lead to increased aggressiveness and distant metastasis. However, the interplay underlying these actions is still unknown. Objective: We explored whether cancer cells might acquire a stem-like phenotype under hypoxia, consequently leading to an aggressive phenotype, including invasiveness and metastasis. Methods: Under normoxia $\left(20 \% \mathrm{O}_{2}\right)$ or hypoxia $(1 \%$ $\mathrm{O}_{2}$ ), the expression of CD133 (cancer stem cell marker), CXC chemokine receptor 4 (CXCR4) and hypoxia-inducible factor$1 \alpha(\mathrm{HIF}-1 \alpha)$ was examined by RT-PCR and immunostaining using human pancreatic cancer cell lines. We also examined if hypoxia facilitates the invasiveness of CD133+ cancer cells. Furthermore, we transfected dominant active HIF-1 $\alpha$ (HIF$1 \alpha \Delta$ ODD) by the retroviral gene transfer and examined the effects both in vitro and in vivo. Results: Compared with normoxia, hypoxia elevated the expression of CD133, CXCR4 and HIF-1 $\alpha$. Moreover, hypoxia facilitated the invasiveness
\end{abstract}

of CD133+ pancreatic cancer cells. The behavior of HIF$1 \alpha \Delta$ ODD-transfected cells under normoxia was compatible with that of the parent cells under hypoxia. Furthermore, a xenograft model of HIF-1 $\alpha \Delta$ ODD cells showed aggressiveness, including metastasis and highly tumorigenic ability. Conclusion: Hypoxia induces tumor aggressiveness associated with the expansion of CD133+ pancreatic cancer cells in a predominantly HIF-1 $\alpha$-dependent manner.

Copyright $\odot 2011$ S. Karger AG, Basel

\section{Introduction}

The presence of intratumoral hypoxia is a negative prognostic indicator for many patients as it has been associated with an increased degree of local failure following radiotherapy, chemotherapy and increased distant metastasis. Hypoxia can drive the metastatic phenotype secondary to both genetic instability and the clonal selection of aggressive tumor cell phenotypes [1]. However, the direct link between hypoxia, genetic instability and an aggressive phenotype remains to be elucidated [2-4].

\section{KARGER}

Fax +41613061234 E-Mail karger@karger.ch www.karger.com
(C) 2011 S. Karger AG, Basel

$1015-2008 / 11 / 0784-0181 \$ 38.00 / 0$

Accessible online at:

www.karger.com/pat
Yuichi Hori, MD, PhD

Division of Hepato-Biliary-Pancreatic Surgery, Department of Surgery

Kobe University Graduate School of Medicine

7-5-1 Kusunoki-cho, Chuo-ku, Kobe 650-0017 (Japan)

Tel. +81 78382 6302, E-Mail horiy@ med.kobe-u.ac.jp 
A subpopulation of cancer stem cells (CSCs) in solid tumors, also referred to as tumor-initiating cells, has been isolated in many human tumors using the cell surface marker CD133. CD133 is a marker of most tumor stem cells, especially human pancreatic CSCs $[5,6]$, as well as mouse pancreatic tissue-specific progenitor cells [7]. CSCs are defined by their capacity for self-renewal, their potential to develop into any cells in the tumor and their proliferative capacity to drive the continued expansion of the tumor population [8]. Another important phenomenon, namely, whether or not the hypoxic regions of tumors harbor CSCs as niches, appears to be a common feature of stem cells and it certainly provides some of the critical stem cell maintenance signals [9-11].

Several lines of evidence suggest that hypoxia promotes the persistence of stem cells and CSCs. Indeed, hypoxic conditions altered the gene expression in human neuroblastoma cells toward an immature and neural crest-like phenotype [12], while also promoting a dedifferentiated phenotype in ductal breast carcinoma in situ [13]. A highly tumorigenic fraction of cells from a neuroblastoma cell line are preferentially found in hypoxic regions of the tumor [14]. More recent studies have also reported that hypoxia could upregulate the stem cell surface marker CD133 in human brain tumors, such as medulloblastoma and glioblastoma [15-17].

The present study hypothesizes that cancer cells might acquire a stem-like phenotype under hypoxia, consequently leading to an aggressive phenotype. A subpopulation of human pancreatic cancer cells was observed to increase the expression of CD133 under hypoxia and thus show increased invasiveness. Furthermore, these responses to hypoxia occurred predominantly in a hypoxia-inducible factor- $1 \alpha$ (HIF-1 $\alpha$ )-dependent manner.

\section{Materials and Methods}

All mouse experimental protocols were conducted according to the Guidelines for Animal Experimentation at Kobe University.

\section{Cell Culture}

Human pancreatic cancer cell lines, PANC-1 and MIAPaCa-2 (American Type Culture Collection, Rockville, Md., USA), were cultured in Dulbecco's Modification of Eagle's Medium (DMEM; Invitrogen, Carlsbad, Calif., USA) supplemented with 10\% fetal bovine serum (FBS). PANC-1 cells are derived from human pancreatic ductal adenocarcinoma and show adherent epithelial clusters. Doubling time is about $52 \mathrm{~h}$. MIAPaCa- 2 cells are from human pancreas carcinoma and show adherent single cells with loosely attached clusters. Doubling time is about $40 \mathrm{~h}$. For hypoxic condition, the cells were moved to a hypoxic chamber (ASTEC, Tokyo, Japan) containing $1 \% \mathrm{O}_{2}, 5 \% \mathrm{CO}_{2}$ and $94 \% \mathrm{~N}_{2}$ for the indicated period to induce hypoxia. The dissolved oxygen concentration was determined by an oxygen meter (Multi 3410 SET4; WTW, Weilheim, Germany).

\section{Plasmids and Retroviral-Mediated Gene Transfer}

The pHA-HIF- $1 \alpha$ and pHA-HIF- $1 \alpha \Delta$ ODD plasmids were gifts from Dr. L.E. Huang (University of Utah) [18]. The gene transfer experiments were carried out by using a retroviral vector. Retroviral vectors encoding SV40 T early region (including small $t$ and large T antigens), cDNA of HIF-1 $\alpha$ and HIF-1 $\alpha \Delta$ ODD were subcloned into CX4bleo. Both the infection with retroviral vectors and selection were performed as described previously [19]. The infection efficiencies were $>80 \%$, based on the findings obtained when using GFP-expressing retroviral vectors.

\section{In vitro Invasion Assays}

A 24-well BioCoat Matrigel invasion chamber (BD Biosciences, Bedford, Mass., USA) was used to study effects of hypoxia on the invasive ability of tumor cells $\left(5 \times 10^{4}\right.$ cells/assays $)$. A suspension of tumor cells in $500 \mu \mathrm{l}$ serum-free DMEM was added to the upper chambers, whereas the lower chambers were each filled with $750 \mu \mathrm{l}$ chemoattractant medium (DMEM plus 10\% FBS). Thereafter, the cells were incubated for 24 or $48 \mathrm{~h}$. The cells that did not demonstrate invasion were then removed from the inserts with a cotton swab. Thereafter, the cells that had invaded into the lower surface of Matrigel-coated membrane were fixed with $4 \%$ paraformaldehyde (PFA), stained with hematoxylin and counted under a light microscope. In order to detect and count CD133+ and/or CXCR4+ cells, we stained the cells that had invaded the Matrigel-coated membrane with CD133 and CXCR4 antibodies. The membranes were then removed with a scalpel and mounted on a glass slide with DAPI. We performed CD133+ and/or CXCR4+ cell counting by either light microscopy (AX80; Olympus, Tokyo, Japan) or confocal immunofluorescence microscopy (LSM 510; Carl Zeiss, Jena, Germany). In some experiments, the

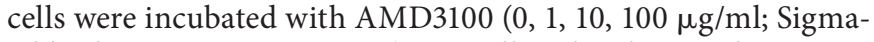
Aldrich, St. Louis, Mo., USA), a small molecular weight CXCR4 antagonist [17].

\section{Quantitative RT-PCR Assay}

Total RNA was extracted using the RNeasy Mini kit (Qiagen, Valencia, Calif., USA). The primer sequences were: CD133, 5'TCCACAGAAATTTACCTACATTGG-3' (forward), 5'-CAGCAGAGAGCAGATGACCA-3' (reverse) (77 bp); CXCR4, 5'-CCAGTAGCCACCGCATCT-3' (forward), 5'-ATAGTCCCCTGAGCCCAT TT-3' (reverse) (99 bp); VEGF, 5'-CGCAAGAAATCCCGGTATAA-3' (forward), 5'-TCTCCGCTCTGAGCAAGG-3' (reverse) (111 bp); $\beta$-actin, $5^{\prime}$-TTAAGGAGAAGCTGTGCTACG3' (forward), 5'-GTTGAAGGTAGTTTCGTGGAT-3' (reverse) (215 bp). Quantitative PCR (q-PCR) was performed with a Quantitect SYBR Green RT-PCR kit (Qiagen) in an ABI Prism 7000 Sequence Detection System (Applied Biosystems, Foster City, Calif., USA). A reaction mixture was first incubated at $50^{\circ} \mathrm{C}$ for $30 \mathrm{~min}$ for reverse transcription. PCR was then initiated at $95^{\circ} \mathrm{C}$ for $15 \mathrm{~min}$ to activate modified Taq polymerase followed by a 45 -cycle amplification $\left(94^{\circ} \mathrm{C}\right.$ for $15 \mathrm{~s}, 55^{\circ} \mathrm{C}$ for $30 \mathrm{~s}$ and $72^{\circ} \mathrm{C}$ for $30 \mathrm{~s})$. At the end of the thermal cycles, a dissociation protocol was 
performed, starting at $60^{\circ} \mathrm{C}$ and then measuring fluorescence with $0.5^{\circ} \mathrm{C}$ increments, to ensure that a single product was detected for each primer pair. The results are presented as the parameter threshold cycle $\left(C_{\mathrm{T}}\right)$ values. $\Delta C_{\mathrm{T}}$ was the difference in the $C_{\mathrm{T}}$ values derived from the specific gene being assayed and $\beta$ actin, whereas $\Delta \Delta C_{\mathrm{T}}$ represented the difference between the paired samples, as calculated by the formula $\Delta \Delta C_{\mathrm{T}}=\Delta C_{\mathrm{T}}$ of a sample $-\Delta C_{\mathrm{T}}$ of a reference. The amount of target gene, normalized to $\beta$-actin and relative to a reference, was expressed as $2^{-\Delta \Delta C T}$.

\section{siRNA Transfection}

PANC- 1 or MIAPaCa- 2 cells $\left(1 \times 10^{5}\right.$ cells $)$ were plated $24 \mathrm{~h}$ before transfection in DMEM supplemented with 10\% FBS. Transfection was performed in serum-free Opti-MEM medium (Invitrogen) with 150 pmol Stealth RNAi mixture for HIF-1 $\alpha$ (Invitrogen; HSS104774, HSS104775 and HSS179231) and $5 \mu$ Lipofectamine (Invitrogen) for $24 \mathrm{~h}$. Then, the transfection medium was replaced with DMEM supplemented with $10 \%$ FBS, and exposed to $1 \%$ hypoxia for $48 \mathrm{~h}$. Controls were transfected with the scrambled siRNA. We used BLOCK-iT Fluorescent Oligo (Invitrogen) to monitor the transfection efficiency of Stealth RNAi.

\section{Implantation Into SCID Mice}

Regarding the tumorigenic ability, HIF- $1 \alpha \Delta$ ODD-transfected cells and mock cells were resuspended in $250 \mu \mathrm{DMEM}$, and then made up to $500 \mu \mathrm{l}$ with Matrigel; $1 \times 10^{3}$ and $1 \times 10^{5}$ cells were injected subcutaneously into the right and left flanks of scid mice using a 23-gauge needle. Animals underwent autopsy at 28 days after cell implantation and tumor growth was accessed. In addition, a suspension of $1 \times 10^{6}$ cells in a volume of $100 \mu \mathrm{l}$ DMEM were engrafted orthotopically into the pancreatic tail of scid mice. Two weeks after the engraftment, the mice were sacrificed. The tissue specimens were fixed in formaldehyde and examined histologically.

\section{Immunohistochemistry}

The cells grown on Lab-Tek chamber slides (Nalge Nunc International, Rochester, N.Y., USA) in hypoxia $\left(1 \% \mathrm{O}_{2}\right)$ or normoxia $\left(20 \% \mathrm{O}_{2}\right)$ were fixed in $4 \%$ PFA for $5 \mathrm{~min}$. The grafts were fixed in $4 \%$ PFA and embedded in Tissue-Tek OCT Compound (Sakura Finetek, Torrance, Calif., USA). They were then sectioned to generate $10-\mu \mathrm{m}$-thick tissue sections. Primary antibodies were used at the following dilutions: mouse anti-CD133/1, 1:100 (Miltenyi Biotec, Bergisch Gladbach, Germany); rabbit anti-CXCR4, 1:100 (Abcam, Cambridge, UK); rabbit anti-HIF-1 $\alpha$, 1:100 (Santa Cruz, Santa Cruz, Calif., USA); rabbit anti-CA9, 1:500 (Novus, Littleton, Colo., USA), and anti-HA-Tag antibody, 1:500 (Cell Signaling Technology, Danvers, Mass., USA). Cellular hypoxia was detected by hypoxyprobe-1 Omni kit (Natural Pharmacia International Inc., Burlington, Mass., USA). Hypoxyprobe (pimonidazole) was administered in vitro at a concentration of $200 \mu \mathrm{M}$ for $2 \mathrm{~h}$. Thereafter, the cells were stained using a rabbit anti-pimonidazole, 1:500 (Natural Pharmacia International Inc.). Tissue sections and fixed cells were incubated with the secondary antibodies labeled with Alexa-conjugated goat anti-rabbit, anti-mouse IgG 1:200 (Molecular Probes, Eugene, Oreg., USA). All images were generated by confocal immunofluorescence microscopy (LSM 510; Carl Zeiss).

\section{Western Blotting}

The cells were washed with ice-cold PBS and scraped off and then put into RIPA lysis buffer (50 mM Tris-HCl; pH 7.5, $125 \mathrm{~mm}$ $\mathrm{NaCl}, 0.1 \%$ Triton X-100, $5 \mathrm{~mm}$ EDTA) including protease inhibitors. The proteins were separated by SDS-PAGE and transferred to polyvinylidene difluoride membranes (Millipore, Billerica, Mass., USA). Nonspecific binding was blocked by incubation for $1 \mathrm{~h}$ at room with 5\% nonfat dry milk in TBST. The membranes were then probed in primary antibodies overnight at $4^{\circ} \mathrm{C}$; antiHIF-1 $\alpha$ (1:1,000), anti-CXCR4 (1:500), anti- $\beta$-actin (1:5,000; Sigma-Aldrich) and anti-CD133 (K-18) (1:200; Santa Cruz). After probing with appropriate secondary antibodies, the signals were then detected by a chemiluminescence substrate (GE Healthcare, Uppsala, Sweden) and the LAS 3000 mini system (Fujifilm, Tokyo, Japan).

\section{Statistical Analyses}

All values were expressed as the means \pm standard error (SE). Statistical significance was determined by two-tailed unpaired Student's t test, and differences were considered to be statistically significant at $\mathrm{p}<0.05$.

\section{Results}

\section{Hypoxia Enhances the Expression of CD133 in}

Pancreatic Cancer Cell Lines

The dissolved oxygen concentration in the medium was $5.96 \pm 0.03 \mathrm{mg} / \mathrm{l}$ at $20 \% \mathrm{O}_{2}$ (normoxia) and $0.05 \pm$ $0.03 \mathrm{mg} / \mathrm{l}$ at $1 \% \mathrm{O}_{2}$ (hypoxia), respectively. By FACS analysis, $\mathrm{CD} 133+$ cells under $20 \% \mathrm{O}_{2}$ in PANC- 1 and MIAPaCa-2 cells were $2.4 \pm 0.3$ and $1.1 \pm 0.2 \%$, respectively. The cells under $1 \% \mathrm{O}_{2}$ for $48 \mathrm{~h}$ significantly increased the expression levels of CD133 in comparison to those under $20 \% \mathrm{O}_{2}$, when analyzed by q-PCR, Western blotting and immunohistochemical staining (fig. 1a, b). More importantly, the upregulation of the CD133 expression levels was reversible when the cells were re-oxygenated under $20 \% \mathrm{O}_{2}$ for $48 \mathrm{~h}$. Immunofluorescence staining by hypoxyprobe (pimonidazole) confirmed these data (fig. 1c). These results indicate that hypoxia promotes the CD133 expression in human pancreatic cancer cell lines, which is consistent with a previous report on human glioma cell lines [12].

\section{Hypoxia Facilitates the Invasiveness of CD133+ \\ Pancreatic Cancer Cells}

As shown in figure $2 a$ and $b$, the invasive activity of the pancreatic cancer cells significantly increased under hypoxia, compared to normoxia. We next stained the invading cells with a CD133 antibody and examined the percentage of CD133+ or CD133- cells. While $92.0 \pm$ $5.0 \%$ of the invasive MIAPaCa-2 cells were CD133+ un- 


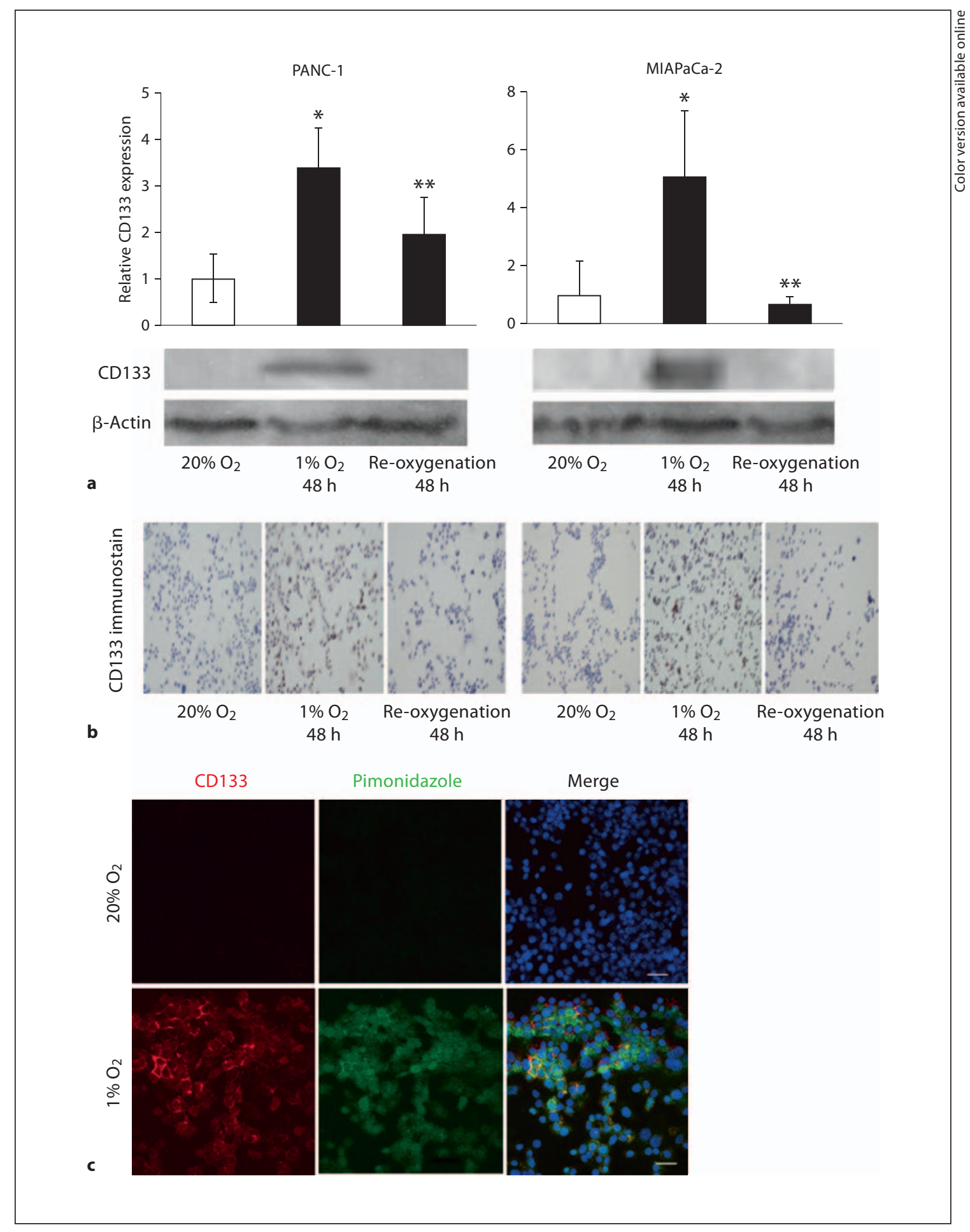

Fig. 1. Effects of hypoxia and re-oxygenation on CD133 expression. Human pancreatic cancer cell lines, PANC-1 and MIA PaCa-2, were cultured under $20 \% \mathrm{O}_{2}$ (normoxia) or $1 \% \mathrm{O}_{2}$ (hypoxia) for $48 \mathrm{~h}$. Re-oxygenation conditions indicate the cells were cultured under $1 \% \mathrm{O}_{2}$ (hypoxia) for $48 \mathrm{~h}$, then re-oxygenized under $20 \% \mathrm{O}_{2}$ (normoxia) for an additional $48 \mathrm{~h}$. a Quantitative analysis of stem cell marker, the CD133 gene expression by q-PCR and CD133 gene product by Western blotting under $1 \% \mathrm{O}_{2}$ (mean \pm SE, $\mathrm{n}=5$; * $\mathrm{p}<$ 0.01 in comparison to cells under $20 \% \mathrm{O}_{2}$ and ${ }^{* *} \mathrm{p}<0.01$ in comparison to cells under $\left.1 \% \mathrm{O}_{2}\right)$. b Upregulation of the CD133 gene product under hypoxia by immunostaining. Original magnification was $\times 100$. c PANC-1 cells were cultured in the presence of hypoxyprobe, pimonidazole. Pimonidazole accumulated in CD133+ cancer cells under $1 \% \mathrm{O}_{2}$. Original magnification was $\times 200$. 


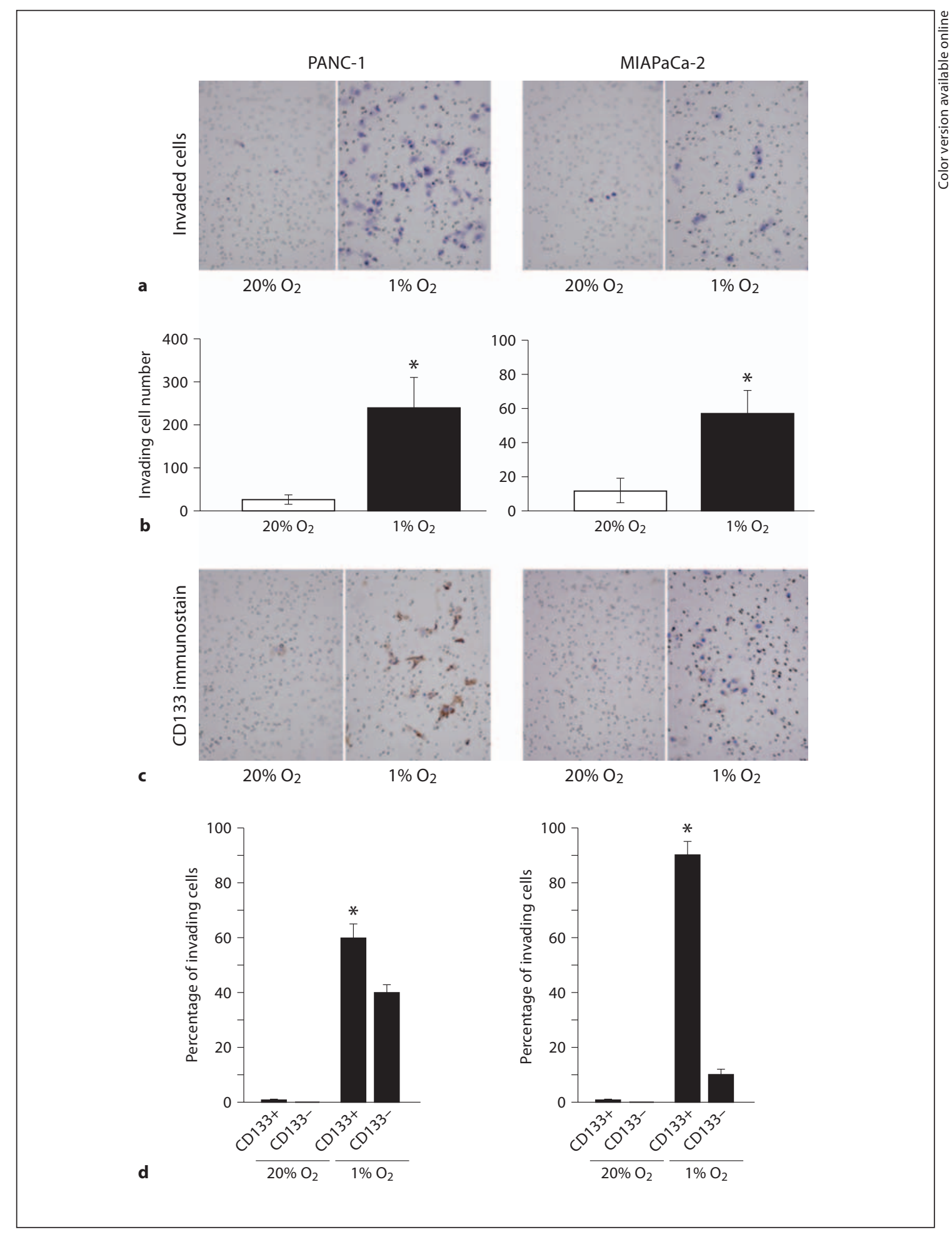

Fig. 2. Hypoxia facilitates the invasiveness of CD133+ pancreatic cancer cells. The invasiveness of PANC-1 cells and MIAPaCa-2 cells was assessed by a BioCoat Matrigel invasion chamber assay. Invading cells were stained with hematoxylin (a) and counted under a light microscope (b) (means $\pm \mathrm{SE}, \mathrm{n}=5 ;{ }^{*} \mathrm{p}<0.01$ in comparison to cells under $20 \% \mathrm{O}_{2}$ ). CD133 expression on invading cells was detected by immunostaining (c) and counted under a light microscopy (d) (means $\pm \mathrm{SE}, \mathrm{n}=5 ;{ }^{*} \mathrm{p}<0.01$ in comparison to cells under $20 \% \mathrm{O}_{2}$ ). Original magnification was $\times 100$. 
Fig. 3. Invading CD133+ pancreatic cancer cells co-express CXCR4 under hypoxia. a CXCR4 gene expression in PANC-1 and MIAPaCa-2 was upregulated under hypoxia in a time-dependent manner (means $\pm \mathrm{SE}, \mathrm{n}=5$; $^{*} \mathrm{p}<0.05$ in comparison to cells under $20 \% \mathrm{O}_{2}$ ). b CXCR4 gene products by immunoblotting were increased under $1 \% \mathrm{O}_{2}$ as well. $\beta$-Actin was shown as an internal control. c Quantification of the invading cell subpopulation. Invading cells were stained with CD133 and CXCR4 antibodies, and each subpopulation was counted under microscopy (means $\pm \mathrm{SE}$, $\mathrm{n}=5$ ).

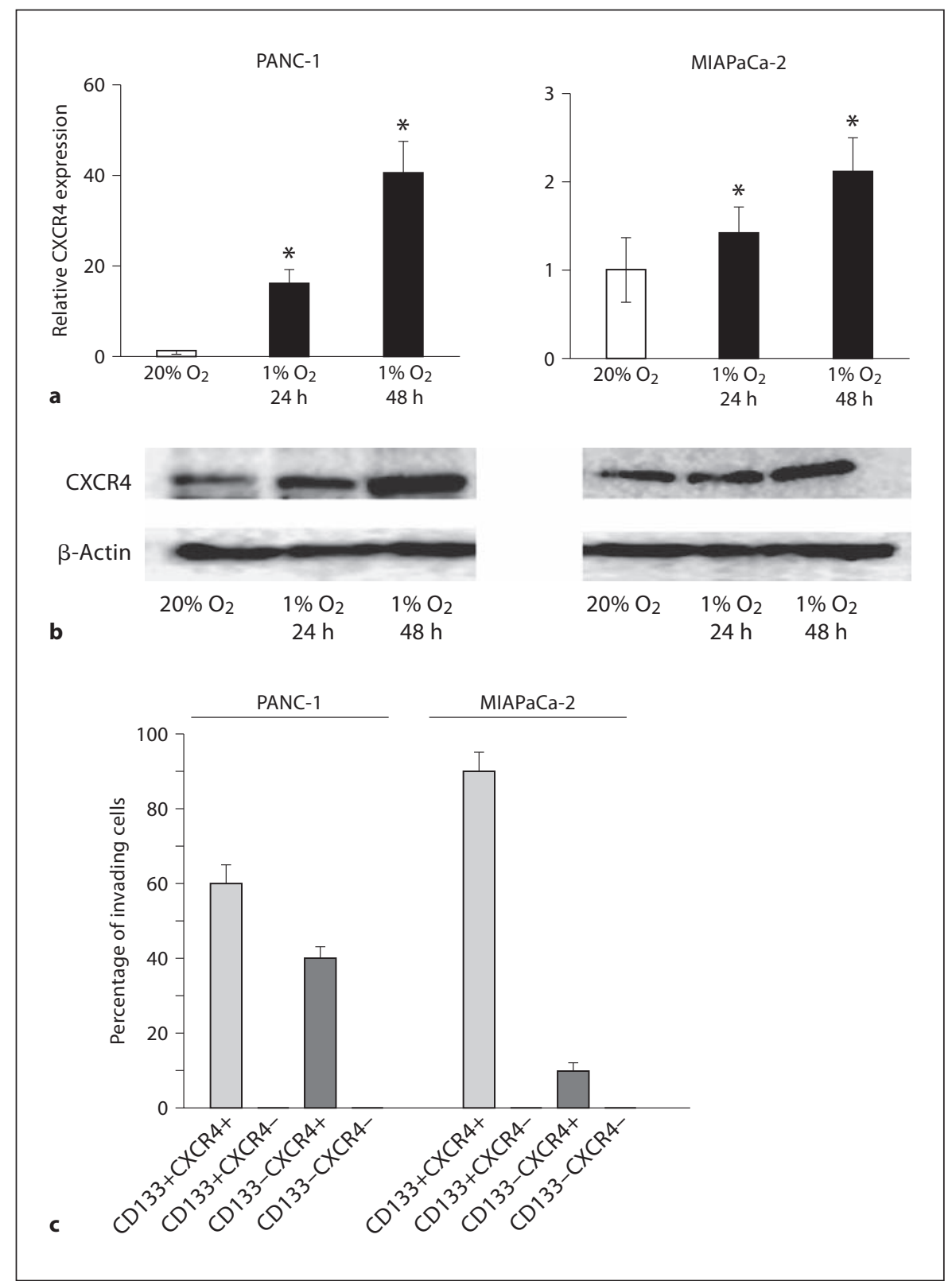

der hypoxia, $62.0 \pm 5.0 \%$ of invasive PANC-1 cells were $\mathrm{CD} 133+$ (fig. 2c, d). These results suggest that CD133+ invading cancer cells are enriched in pancreatic cancer cell lines under conditions of hypoxia, especially in MIAPaCa-2 cells, compared to normoxia.

\section{Invading Cancer Cells Express CXCR4 under Hypoxia} in vitro

Recent reports have suggested CXCR4 to be a key regulator of tumor invasiveness leading to local progression and tumor metastasis $[20,21]$. CXCR4 gene and gene product expression increased under hypoxia in a timedependent manner, in comparison to normoxia (fig. 3a, b). In addition, these phenotypes were also reversible when the cells were re-oxygenated under $20 \% \mathrm{O}_{2}$ for $48 \mathrm{~h}$, which was consistent with CD133 gene expression (online suppl. fig. S1; for all supplementary material, see www.karger.com/doi/10.1159/000325538). On the other hand, other invasion-related genes, including E-cadherin, $\mathrm{N}$-cadherin, snail, twist, matrix metalloproteinase-2 and $c$-Met, did not significantly change the expression level (data not shown) [22]. We next stained and quantified the 
Fig. 4. Both acquired stem-like phenotype and tumor aggressiveness including invasiveness and metastasis of pancreatic cancer under hypoxia occur in a HIF-1 $\alpha$-dependent manner. a MIAPaCa-2 cells were transfected with HIF-1 $\alpha$ or oxygen-dependent degradation domain-deficient HIF-1 $\alpha$ (HIF-1 $\alpha \Delta$ ODD) plasmids, then cultured under normoxia for $48 \mathrm{~h}$. HIF-1 $\alpha$ protein level was detected only in HIF- $1 \alpha \Delta$ ODDtransfected cells under normoxia. $\beta$-Actin was shown as an internal control. CD133 and HIF-1 $\alpha$ target, VEGF gene expressions were increased in HIF- $1 \alpha \Delta$ ODD-transfected cells under normoxia (means \pm SE, $n=$ 5 ; ${ }^{*} \mathrm{p}<0.05$ in comparison to HIF-1 $\alpha$ transfected cells). $\mathbf{b}$ Overexpression of HIF$1 \alpha \Delta$ ODD significantly induced the number of CD133+ cells. Original magnification was $\times 200$. c Overexpression of HIF$1 \alpha \Delta$ ODD induced a significant increase of CD133 expression. Original magnification was $\times 630$. d Metastatic lesions in the liver (arrows) after orthotopic xenograftment. Xenografted primary pancreatic tumor and liver metastasis were immunostained for CD133 (red) and HA-Tag (green). All nuclei were counterstained with DAPI (blue). Original magnification was $\times 200$. e Dominant active HIF-1 $\alpha \Delta$ ODD-transfected cells showed highly tumorigenic ability. A representative tumorigenic ability of HIF- $1 \alpha \Delta$ ODD-expressing cells. $10^{3}$ and $10^{5}$ HIF- $1 \alpha \Delta$ ODD-expressing cells on the right side of the flank showed higher tumorigenic ability than mock cells on the left side of the flank. Hematoxylin and eosin staining of the tumor generated from HIF$1 \alpha \Delta$ ODD-expressing cells indicated epithelial pancreatic cancer cells. Original magnification was $\times 200$.

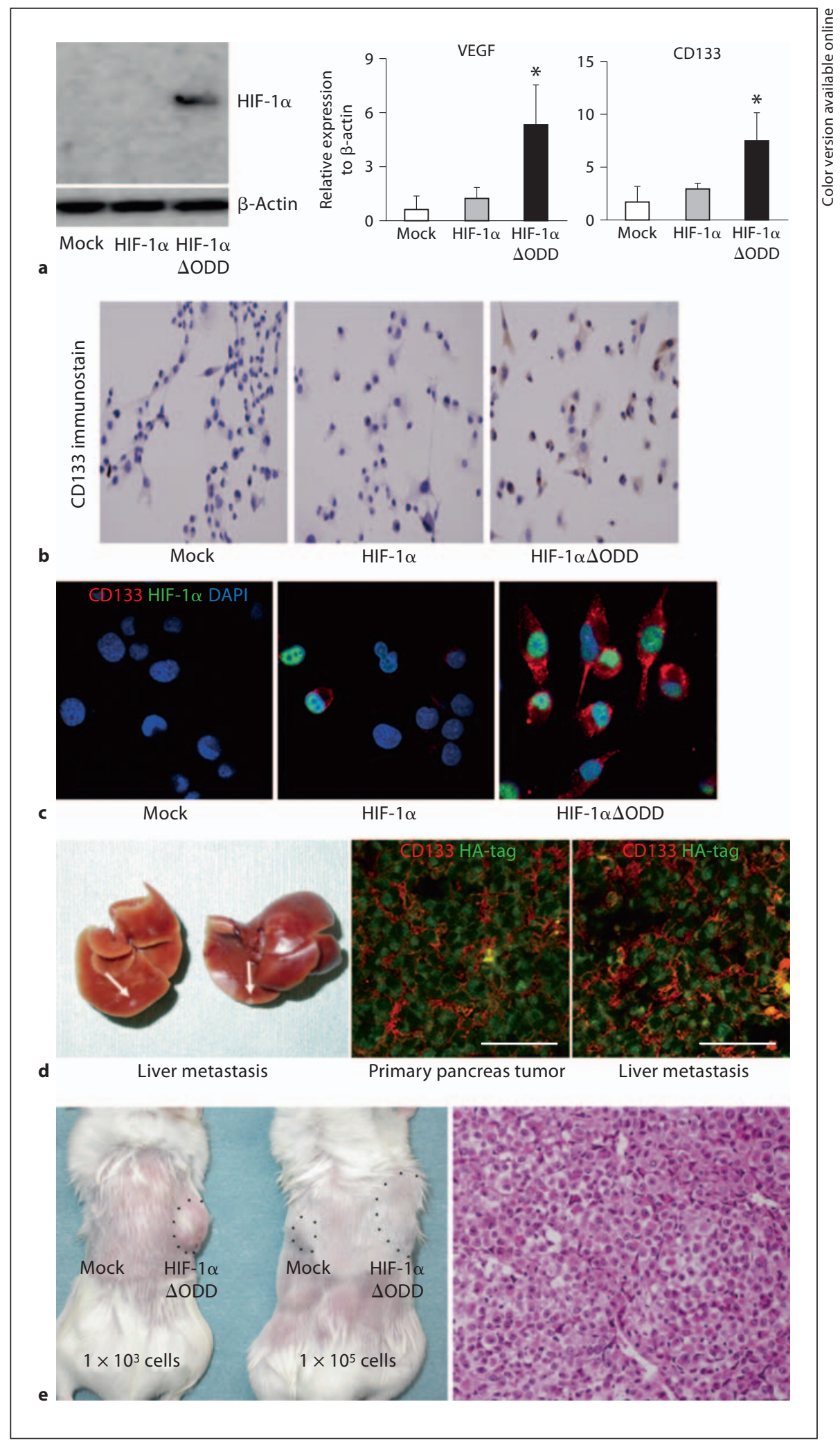


Fig. 5. Effect of CXCR4 expression on pancreatic cancer under hypoxia is in a HIF$1 \alpha$-dependent manner. a The CXCR4 genes and gene products were increased in the HIF-1 $\alpha \Delta$ ODD-transfected cells (means $\pm \mathrm{SE}, \mathrm{n}=5$; $^{*} \mathrm{p}<0.05$ in comparison to the HIF-1 $\alpha$-transfected cells). b The dose dependency of the CXCR4 antagonist AMD3100 on the HIF- $1 \alpha \Delta$ ODD-transfected cell growth after $48 \mathrm{~h}$ culture (means $\pm \mathrm{SE}, \mathrm{n}=5$; ${ }^{*} \mathrm{p}<0.05$ in comparison to untreated control). c Effect of AMD3100 on CD133 gene expression (means $\pm \mathrm{SE}, \mathrm{n}=5$ ). A quantitative analysis was performed by q-PCR. d The total number of invaded cells and invaded CD133+ cells increased in the HIF$1 \alpha \Delta$ ODD-transfected MIAPaCa-2 cells. e Treatment with $1.0 \mu \mathrm{g} / \mathrm{ml}$ AMD3100 drastically inhibited the degree of invasiveness of CD133+ cells (means $\pm \mathrm{SE}$, $\mathrm{n}=5$; $^{*} \mathrm{p}<0.01$ in comparison to that observed in HIF-1 $\alpha$-transfected cells and ${ }^{* *} \mathrm{p}<0.01$ in comparison to HIF- $1 \alpha \Delta \mathrm{ODD}$ transfected cells).

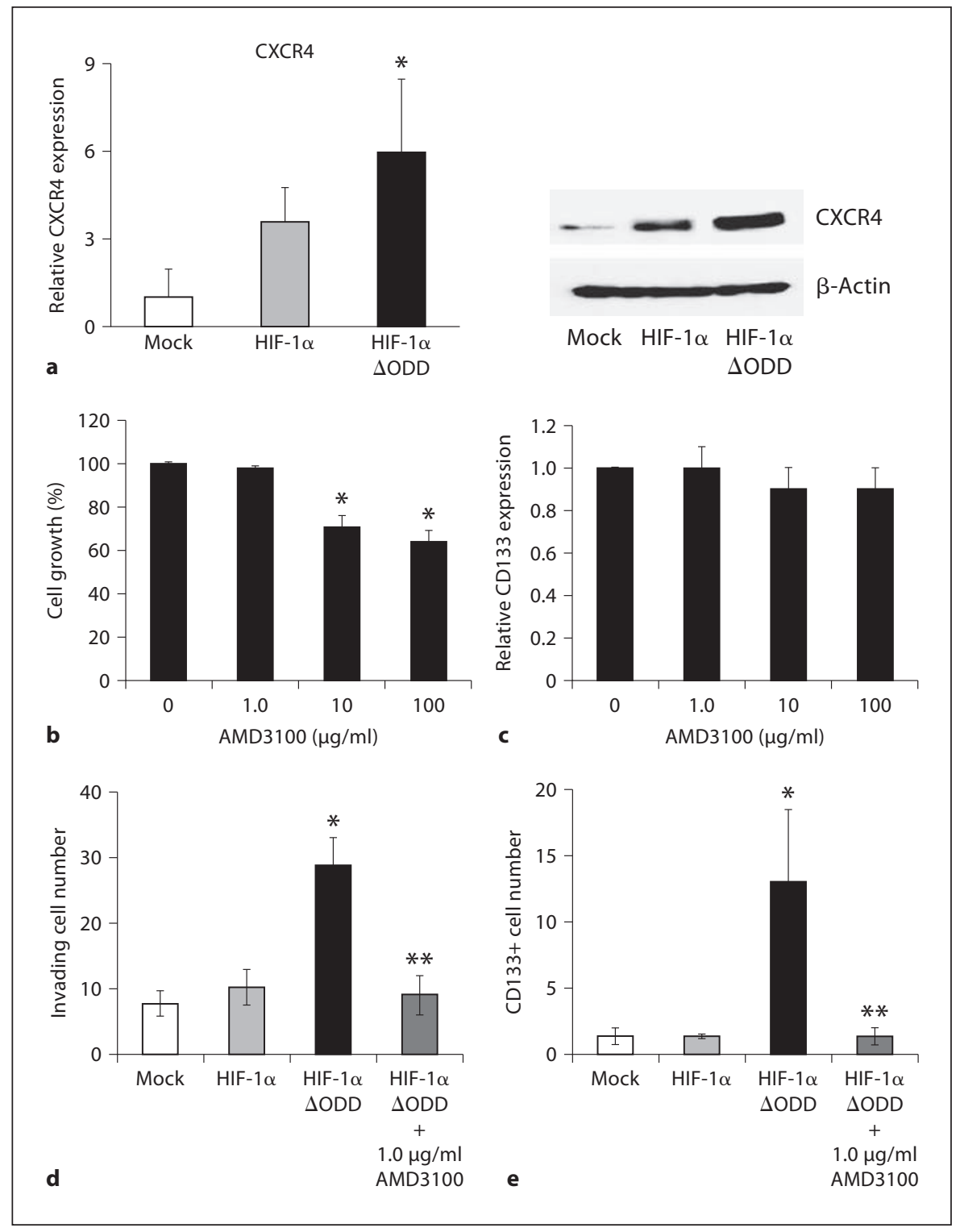

invading cells with CD133 and CXCR4 antibodies. Almost all invading cells under hypoxia were CXCR4+ in both cell lines. In PANC-1 cells, the CD133+CXCR4+ and CD133-CXCR4+ subpopulations comprised $62.0 \pm 5.0$ and $38.0 \pm 3.0 \%$ of the cells, respectively. On the other hand, in MIAPaCa-2 cells, the CD133+CXCR4+ and CD133-CXCR4+ subpopulations were $92.0 \pm 5.0$ and 8.0 $\pm 2.0 \%$ of the cells, respectively (fig. 3c). We also examined whether CD133+CXCR4+ cancer cells exist in invasive lesions of human pancreatic cancers. We observed infiltrating CD133+CXCR4+ pancreatic cancer cells in the surrounding stroma $(n=5)$ (online suppl. fig. S4a).

\section{Acquired Tumor Aggressiveness Including} Invasiveness and Remote Metastasis under Hypoxia Is HIF-1 $\alpha$ Dependent

It is evident that the critical molecular mediator of hypoxia, HIF-1 $\alpha$, regulates multiple steps of tumorigenesis including tumor formation, progression and response to therapy. The present study first confirmed the upregulation of HIF-1 $\alpha$ under hypoxic conditions (online suppl. fig. S2). Moreover, we performed knockdown experiments with HIF- $1 \alpha$ siRNA and observed significantly reduced CD133 gene expression. In addition, CXCR4 and VEGF expression, which is the direct target of HIF-1 $\alpha$, 
were also reduced (online suppl. fig. S3). In addition, CD133+ cells co-expressing hypoxic markers, such as HIF-1 $\alpha$ and CA9, were enriched in the invasive lesions of human pancreatic cancer $(\mathrm{n}=10)$ (online suppl. fig. $\mathrm{S} 4 \mathrm{~b})$.

HIF- $1 \alpha$ is rapidly degraded under normoxic condition, with a half-life of a few minutes. The oxygen-dependent degradation domain-deficient HIF-1 $\alpha$ (HIF$1 \alpha \Delta \mathrm{ODD})$, which is stable and functional even under normoxia, was overexpressed to elucidate the involvement of HIF- $1 \alpha$ in the CD133 gene expression. As expected, the expression of HIF- $1 \alpha$ protein was detected only in HIF- $1 \alpha \Delta$ ODD-transfected cells under $20 \% \mathrm{O}_{2}$ normoxia (fig. 4a). A q-PCR analysis showed that not only CD133, but also VEGF expression increased in HIF-1 $\alpha \Delta$ ODDtransfected cells (fig. 4a). Furthermore, the induction of CD133 expression was confirmed by immunohistochemical staining (fig. $4 \mathrm{~b}$ ). Of note, the cells expressing dominant active HIF-1 $\alpha$ co-expressed CD133 on the cell surface (fig. 4c). Consistent with the HIF-1 $\alpha$ overexpression, the number of invading CD133+ cells increased even under normoxia (fig. $5 \mathrm{~d}$, e). The data on HIF- $1 \alpha \Delta$ ODDtransfected cells under normoxia was compatible with those of the parent cells under hypoxia (fig. 1b, 2b). Another target of HIF-1 $\alpha$, CXCR4 genes and gene products also increased in HIF-1 $\alpha \Delta$ ODD cells (fig. $5 \mathrm{a}$ ). We next tested whether the CXCR4 antagonist, AMD3100, could reduce the number of invading CD133+ HIF-1 $\alpha \Delta$ ODDtransfected cells. The dose dependency of AMD3100 on cell growth was initially determined and cell growth was unaffected at a concentration of $1.0 \mu \mathrm{g} / \mathrm{ml}$ (fig. 5b). We also investigated the effect of AMD3100 on CD133 gene expression by quantitative RT-PCR. A concentration of $1.0 \mu \mathrm{g} / \mathrm{ml}$ of AMD3100 had no effect on CD133 gene expression (fig. 5c). Notably, the treatment with $1.0 \mu \mathrm{g} / \mathrm{ml}$ of AMD3100 drastically reduced the number of invading CD133+ cells (fig. 5d, e). HIF-1 $\alpha \Delta$ ODD or mock expressing cells were engrafted into the pancreas of immunodeficient mice. Interestingly, 4 of 10 mice engrafted with HIF-1 $\alpha \Delta$ ODD-expressing cells showed metastatic lesions in the liver $(n=4 / 10)$, while none of the mice engrafted with mock cells showed any liver metastasis $(n=0 / 10)$ after 2 weeks of engraftment (fig. $4 \mathrm{~d}$; online suppl. fig. S5). These metastatic cells in the liver as well as the primary orthotopic pancreas tumor expressed CD133 under HIF-1 $\alpha$ activation (fig. 4d). Furthermore, tumorigenic ability of HIF-1 $\alpha \Delta$ ODD-expressing cells is shown in figure $4 \mathrm{e} ; 10^{3}$ and $10^{5} \mathrm{HIF}-1 \alpha \Delta \mathrm{ODD}$-expressing cells showed highly tumorigenic ability than mock cells. Hematoxylin and eosin staining of the tumor indicated epithelial cancer cells (fig. 4e), phenotypically indistinguish- able from tumors derived from mock cells. These results indicate that the tumor aggressiveness, including invasiveness and remote metastasis under hypoxia, was predominantly HIF- $1 \alpha$ dependent.

\section{Discussion}

Pancreatic cancer is currently the fourth leading cause of cancer-related mortality and is characterized by intratumoral hypovascularity. In addition, human pancreatic tumor oxygenation measured intraoperatively with an electrode shows high levels of hypoxia in pancreatic cancers [23]. Cancer cells might acquire stemness or express 'stem cell-like' properties under hypoxia, consequently leading to an aggressive phenotype in solid tumors. The current study initially confirmed that hypoxia induced an increased number of invading CD133+ cancer cells, hypoxic cells themselves expressed CD133 in vitro, and that $\mathrm{CD} 133+$ cancer cells were preferentially found in the invasive legions of human pancreatic cancer specimen. CD133 is a marker protein typically used to identify and isolate human pancreatic CSCs [5], as well as mouse pancreatic tissue-specific stem cells [7]. Furthermore, DNA microarray data of CD133 $3^{\text {high }}$ PDGFR- stem/progenitor cells from the fetal mouse pancreas showed the upregulation of the 'stemness genes', including Bmi1, Notch1-3, $\beta$-catenin, Frizzled, APC, Ptch1 and Smo, indicating that CD133 is a putative stem cell marker [7]. Although the concept of CSCs or tissue-specific stem cells in solid organs has been extended from hematopoietic stem cells, only rarely stem cells have been identified as clonogenic precursors that give rise to both self-renewing and differentiated progeny. Future studies must transplant individual CD133+ cancer cells and confirm the tumor progression to definitively prove that CD133+ cancer cells under hypoxia indeed have stem cell properties. In the present study, we cannot conclude that CD133+ cancer cells under hypoxia are CSCs. However, our preliminary data indicate that cancer cells under hypoxia preferably segregate asymmetrically, while cancer cells under normoxia do not, suggesting that cancer cells might acquire a stem-like phenotype under hypoxia (data not shown).

More importantly, the present study demonstrated that these phenotypes under hypoxia are reversible when the cells are re-oxygenated under $20 \% \mathrm{O}_{2}$ normoxia conditions. These results are consistent with a recent report using human glioma cell lines [24]. What remains unclear is whether CSCs are the direct progeny of mutated stem cells or more mature cells that reacquire stem cell 
properties during tumor formation. Recently, Zhu et al. [25] reported that CD133 marks stem cells in the adult mouse small intestine that are susceptible to transformation into tumors retaining a fraction of mutant CD133 tumor cells. In view of the in vitro results that the appearance of $\mathrm{CD} 133$ + cell population is reflected by the $\mathrm{O}_{2}$ concentration and these phenotypes are reversible without a significant impact on cell number, it is possible that mature CD133 - cancer cells can re-acquire stem cell properties under hypoxia.

We next questioned how hypoxia is involved in the stem cell microenvironment. The existence of a stem cell niche, consisting of specialized cells that participate in stem cell regulation, has been verified for mammalian adult stem cells in the intestinal, neural epidermal and hematopoietic systems [10]. In light of these findings, it has been proposed that there is also a CSC niche; however, their location and models for the relationship between cancer cells and their niches remain unresolved [26]. The present study demonstrated for the first time that CD133+ cells themselves are hypoxic cells in vitro, as characterized by pimonidazole labeling. Furthermore, the number of hypoxic CD133+ cells, which are double positive with HIF-1 $\alpha$ or CA9, has been observed to increase in the invasive lesion of human pancreatic cancer (online suppl. fig. S4), in comparison to the bulk tumors, thus indicating that hypoxic CD133+ cells might be an indicator of malignant potential in human pancreatic cancer cells. In general, it is thought that soluble factors from tumor-associated fibroblasts or stromal cells in the hypoxic regions of tumor may promote self-renewal of tumor cells in vivo. Furthermore, Das et al. [14] reported that migrating neuroblastoma cells under hypoxic conditions home to hypoxic regions in the tumor when injected into tumor-bearing nude mice. Although this study did not rule out the possibility that tumor-associated fibroblasts or stromal cells in the hypoxic regions function as a CSCs niche, the in vitro data suggest the possibility that CSCs may be niche independent and the hypoxic cancer cells themselves can acquire the ability to cell-autonomously provide the necessary factors for expansion and self-renewal that are normally restricted by the niche.

The appearance of CD133+CXCR4+ cells in the present study also confirmed that an aggressive phenotype similar to the invasiveness of $\mathrm{CD} 133+$ cells was reacquired under hypoxia, since Hermann et al. [5] reported the CD133+CXCR4+ cell population to be a highly metastatic human pancreatic cancer cell line which is highly invasive when orthotopically injected into nude mice. Another report indicated the CXCR4 expression to increase liver and lung metastasis in a mouse model of pancreatic cancer [27]. In the present study, the CD133+CXCR4+ subpopulation was predominant in the invaded MIAPaCa- 2 cells, but not in PANC-1 cells, thus suggesting that the CD133-CXCR4+ subpopulation was invasive. On the other hand, almost all invading cells under hypoxia were CXCR4+ in both cell lines, indicating that CXCR4, but not CD133, might define the invasive phenotype in pancreatic cancer.

HIF- $1 \alpha$ is the best characterized among the transcriptional regulators under hypoxia $[28,29]$. HIF-1 $\alpha$ regulates the transcription of many genes involved in the maintenance of stem cell pools, cellular de-differentiation, genetic instability, metabolic reprogramming, invasion and metastasis $[30,31]$. HIF- $1 \alpha$ is also upregulated in various types of human stem cells including embryonic stem cells, hematopoietic stem/progenitor cells and mesenchymal stem cells [32]. HIF-1 $\alpha$ gene expression is upregulated in CD133 high PDGFR- mouse pancreatic stem/ progenitor cells [7]. HIF- $1 \alpha \Delta$ ODD was used to determine whether or not this behavior under hypoxic conditions is also present in a HIF-1 $\alpha$ dependent. The CD133 gene expression and invasive CD133+ cell number indicated that the HIF-1 $\alpha \Delta$ ODD-transfected cells' behavior under normoxia was compatible with that under hypoxia. Although the direct interaction between HIF-1 $\alpha$ and CD133 is still unknown, the current data and a recent report by Soeda et al. [33] strongly support the interplay between these molecules. In the current study, HIF-1 $\alpha$ knockdown partially abrogated the elevated CD133 expression under hypoxia conditions (online suppl. fig. S3b), thus suggesting that additional mechanisms regulate CD133 expression. Griguer et al. [24] reported that CD133 expression in human glioma cells is regulated by hypoxia and mitochondrial dysfunction. One possibility is to assume that CD133 expression in pancreatic cancer is also regulated not only by hypoxia, but also by mitochondrial dysfunction. Another possibility is the involvement of HIF- $2 \alpha$. HIF- $2 \alpha$ maintains the undifferentiated state of cells and regulates tumorigenic capacity through the upregulation of Oct4, an important stem cell factor $[34,35]$. We detected the baseline HIF- $2 \alpha$ expression by RT-PCR, but no changes were observed when pancreatic cancer cells were cultured under hypoxic conditions in the current study (data not shown). Of interest, the CD133+HIF- $1 \alpha+$ cell population in the primary xenograft following HIF- $1 \alpha \Delta$ ODD gene transfer increased more than those in the untreated xenograft, and consequently gave rise to liver metastasis. Taken together, these findings suggest that the acquired aggressiveness occurs predominantly in an HIF- $1 \alpha$-de- 
pendent manner. CXCR4 is a direct HIF target [36]. As shown in figure 5, CXCR4 antagonist had no effect on CD133 gene expression in HIF-1 $\alpha \Delta$ ODD cells, indicating that CXCR4 and CD133 were independently induced by HIF-1 $\alpha$.

We herein demonstrated that human pancreatic cancer cells upregulated the stem cell marker CD133 under hypoxia, while also showing tumor invasiveness. Furthermore, these phenotypes, including invasiveness and metastasis, occur in a predominantly HIF- $1 \alpha$-dependent manner.

\section{Acknowledgements}

We thank Dr. Huang (Department of Neurosurgery, University of Utah) for the gift of HIF-1 $\alpha$ and HIF-1 $\alpha \Delta$ ODD plasmids. We are grateful to Dr. Tsuyoshi Akagi (KAN Research Institute Inc., Kobe, Japan) for retroviral gene transfer. This research was supported by grants-in-aid for scientific research from the Ministry of Education, Culture, Sports, Science and Technology of Japan to Y.H. (21591773), Y.K. (20591611). Y.K. was also supported by grants for the Global Center of Excellence Program for Education and Research on Signal Transduction Medicine in the Coming Generation 'Bringing up clinician-scientists in the alliance between basic and clinical medicine'.

\section{References}

-1 Bristow RG, Hill RP: Hypoxia and metabolism. Hypoxia, DNA repair and genetic instability. Nat Rev Cancer 2008;8:180-192.

\2 Koshiji M, To KK, Hammer S, Kumamoto K, Harris AL, Modrich P, Huang LE: HIF-1 $\alpha$ induces genetic instability by transcriptionally downregulating MutS $\alpha$ expression. Mol Cell 2005; 17:793-803.

- 3 To KK, Sedelinikova OA, Samons M, Bonner WM, Huang LE: The phosphorylation status of PAS-B distinguishes HIF- $1 \alpha$ from HIF- $2 \alpha$ in NBS1 repression. EMBO J 2006;25:47844794.

-4 Huang LE, Bindra RS, Glazer PM, Harris AL: Hypoxia-induced genetic instability-a calculated mechanism underlying tumor progression. J Mol Med 2007;85:139-148.

$\checkmark 5$ Hermann PC, Huber SL, Herrler T, Aicher A, Ellwart JW, Guba M, Bruns CJ, Heeschen C: Distinct populations of cancer stem cells determine tumor growth and metastatic activity in human pancreatic cancer. Cell Stem Cell 2007;1:313-323.

-6 Shimizu K, Itoh T, Shimizu M, Ku Y, Hori Y: CD133 expression pattern distinguishes intraductal papillary nucinous neoplasms from ductal adenocarcinomas of the pancreas. Pancreas 2009;38:e207-e214.

7 Hori Y, Fukumoto M, Kuroda Y: Enrichment of putative pancreatic progenitor cells from mice by sorting for prominin1 (CD133) and platelet-derived growth factor receptor beta. Stem Cells 2008;26:2912-2920.

-8 Jordan CT, Guzman ML, Noble M: Cancer stem cells. N Engl J Med 2006;355:12531261.

-9 Moore KA, Lemischka IR: Stem cells and their niches. Science 2006;311:1880-1885.

10 Joseph NM, Morrison SJ: Toward an understanding of the physiological function of Mammalian stem cells. Dev Cell 2005;9: 173-183.
11 Li L, Xie T: Stem cell niche: structure and function. Annu Rev Cell Dev Biol 2005;21 605-631.

12 Jogi A, Ora I, Nilsson H, Lindeheim A, Makino Y, Poellinger L, Axelson H, Pahlman S: Hypoxia alters gene expression in human neuroblastoma cells toward an immature and neural crest-like phenotype. Proc Natl Acad Sci USA 2002;99:7021-7026.

13 Helczynska K, Kronblad A, Jogi A, Nilsson E, Beckman S, Landberg G, Pahlman S: Hypoxia promotes a dedifferentiated phenotype in ductal breast carcinoma in situ. Cancer Res 2003;63:1441-1444.

14 Das B, Tsuchida R, Malkin D, Koren G, Baruchel S, Yeger H: Hypoxia enhances tumor stemness by increasing the invasive and tumorigenic side population fraction. Stem Cells 2008;26:1818-1830.

15 Platet N, Liu SY, Atifi ME, Oliver L, Vallette FM, Berger F, Wion D: Influence of oxygen tension on CD133 phenotype in human glioma cell cultures. Cancer Lett 2007;258:286290.

16 McCord AM, Jamal M, Shankavarum UT, Lang FF, Camphausen K, Tofilon PJ: Physiologic oxygen concentration enhances the stem-like properties of CD133+ human glioblastoma cells in vitro. Mol Cancer Res 2009; 7:489-497.

17 Qiang L, Yang Y, Ma YJ, Chen FH, Zhang LB, Liu W, Qi Q, Lu N, Tao L, Wang XT, You QD, Guo QL: Isolation and characterization of cancer stem like cells in human glioblastoma cell lines. Cancer Lett 2009;279:13-21.

18 Huang LE, Gu J, Schau M, Bunn HF: Regulation of hypoxia-inducible factor 1alpha is mediated by an $\mathrm{O}_{2}$-dependent degradation domain via the ubiquitin-proteasome pathway. Proc Natl Acad Sci USA 1998;95:79877992.

19 Akagi T, Sasai K, Hanafusa H: Refractory nature of normal human diploid fibroblasts with respect to oncogene-mediated transformation. Proc Natl Acad Sci USA 2003;100: 13567-13572.
20 Marchesi F, Monti P, Leone BE, Zerbi A, Vecchi A, Piemonti L, Mantovani A, Allavena P: Increased survival, proliferation, and migration in metastatic human pancreatic tumor cells expressing functional CXCR4. Cancer Res 2004;64:8420-8427.

21 Burger JA, Kipps TJ: CXCR4: a key receptor in the crosstalk between tumor cells and their microenvironment. Blood 2006;107: 1761-1767.

22 Ide T, Kitajima Y, Miyoshi A, Ohtsuka T, Mitsuno M, Ohtaka K, Koga Y, Miyazaki K: Tumor-stromal cell interaction under hypoxia increases the invasiveness of pancreatic cancer cells through the hepatocyte growth factor/c-Met pathway. Int J Cancer 2006;119:2750-2759.

23 Koong AC, Mehta VK, Le QT, Fisher GA, Terris DJ, Brown JM, Bastidas AJ, Vierra M: Pancreatic tumors show high levels of hypoxia. Int J Radiat Oncol Biol Phys 2000;48: 919-922.

>24 Griguer CE, Oliva CR, Gobin E, Marcorelles P, Benos DJ, Lancaster JR, Gillespie GY: CD133 is a marker of bioenergetic stress in human glioma. PLoS ONE 2008;3:e3655.

-25 Zhu L, Gibson P, Currle DS, Tong Y, Richardson RJ, Bayazitov IT, Poppleton H, Zakharenko S, Ellison DW, Gilbertson RJ: Prominin 1 marks intestinal stem cells that are susceptible to neoplastic transformation. Nature 2009;457:603-607.

26 Sneddon JB, Werb Z: Location, location, location: the cancer stem cell niche. Cell Stem Cell 2007;1:607-611.

27 Saur D, Seidler B, Schneider G, Algul H, Beck $\mathrm{R}$, Senekowitsch-Schmidtke R, Schwaiger M, Schmid RM: CXCR4 expression increases liver and lung metastasis in a mouse model of pancreatic cancer. Gastroenterology 2005; 129:1237-1250.

28 Wang GL, Jiang BH, Rue EA, Semenza GL: Hypoxia-inducible factor 1 is a basic-helixloop-helix-PAS heterodimer regulated by cellular O2 tension. Proc Natl Acad Sci USA 1995;92:5510-5514. 
-29 Wang GL, Semenza GL: Purification and characterization of hypoxia-inducible factor 1. J Biol Chem 1995;270:1230-1237.

-30 Semenza GL: Regulation of cancer cell metabolism by hypoxia-inducible factor 1 . Semin Cancer Biol 2009;19:12-16.

-31 Semenza GL: Evaluation of HIF-1 inhibitors as anticancer agents. Drug Discov Today 2007; 12:853-859.

-32 Kim CG, Lee JJ, Jung DY, Jeon J, Heo HS, Kang HC, Shin JH, Cho YS, Cha KJ, Do BR, Kim KS, Kim HS: Profiling of differentially expressed genes in human stem cells by cDNA microarray. Mol Cells 2006;21:343355.
3 Soeda A, Park M, Lee D, Mintz A, Androusellis-Theotokis A, McKay RD, Engh J, Iwama T, Kunisada T, Kassam AB, Pollack IF, Park DM: Hypoxia promotes expansion of the CD133-positive glioma stem cells through activation of HIF-1alpha. Oncogene 2009;28:3949-3959.

34 Li Z, Bao S, Wu Q, Wang H, Eyler C, Sathornsumetee S, Shi Q, Cao Y, Lathia J, McLendon RE, Hjelmeland AB, Rich JN: Hypoxiainducible factors regulate tumorigenic capacity of glioma stem cells. Cancer Cell 2009; 15:501-513.
35 Pietras A, Hansford LM, Johnsson AS, Bridges E, Sjolund J, Gisselsson D, Rehn M, Beckman S, Noguera R, Navarro S, Cammenga J, Fredlund E, Kaplan DR, Pahlman S: HIF- $2 \alpha$ maintains an undifferentiated state in neural crest-like human neuroblastoma tumor-initiating cells. Proc Natl Acad Sci USA 2009;106:16805-16810.

36 Staller P, Sulitkova J, Lisztwan J, Moch H, Oakeley EJ, Krek W: Chemokine receptor CXCR4 downregulated by von Hippel-Lindau tumour suppressor pVHL. Nature 2003; 425:307-311. 